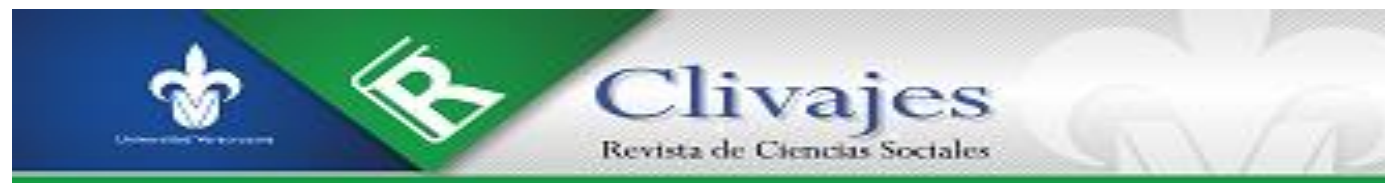

María Inés Barrios de la $\mathrm{O}$

innes.barrios@gmail.com

El Colegio de la Frontera Norte, México

DE DESPLAZADOS INTERNOS A SOLICITANTES DE ASILO. LA COMPLEJIDAD

DEL FENÓMENO MIGRATORIO POR MOTIVOS DE VIOLENCIA

EN Ciudad JuÁREZ, ChIHUAhua, MÉXICO

DOI: https://doi.org/10.25009/clivajesrcs.i15.2693

Clivajes. Revista de Ciencias Sociales. Año VIII, número 15, enero-junio 2021, pp. 104-131.

https://clivajes.uv.mx/index.php/Clivajes

Instituto de Investigaciones Histórico-Sociales, Universidad Veracruzana

Clivajes. Revista de Ciencias Sociales/ISSN: 2395-9495/IIH-S, UV/Xalapa, Veracruz, México

Recibido: 24/03/2021

Aceptado: 05/04/2021

Dictaminado: $21 / 05 / 2021$

(9) $\odot \Theta \Theta$

Clivajes. Revista de Ciencias Sociales (ISSN: 2395-9495), Año VIII, Núm. 15, enero-junio, 2021 Instituto de Investigaciones Histórico-Sociales, Universidad Veracruzana, México 


\title{
DE DESPLAZADOS INTERNOS A SOLICITANTES DE ASILO. LA COMPLEJIDAD DEL FENÓMENO MIGRATORIO POR MOTIVOS DE VIOLENCIA EN CIUDAD JuÁrez, ChIHUAHUA, MÉXICO
}

María Inés Barrios de la $\mathrm{O}^{*}$

\begin{abstract}
Resumen
Este artículo tiene como propósito analizar la transitabilidad que experimentan los migrantes forzados, a través de categorías migratorias como "desplazados forzados internos" o "solicitantes de protección internacional" mediante refugio, asilo o retorno forzado. Para ello, se utiliza como caso de estudio la información de la Encuesta de Mexicanos Desplazados Solicitantes de Asilo (ENMEDESA), realizada en 2019 en Ciudad Juárez, Chihuahua, a partir de cuyo análisis se concluye que los actuales contextos de movilidad forzada, derivados de la violencia, sobrepasan las categorías migratorias, insuficientes para explicar y atender este fenómeno, evidenciando su complejidad y multidimensionalidad, en donde los sujetos adquieren perfiles migratorios con un alto grado de transitabilidad que desdibuja la responsabilidad de los Estados para atender, proteger y garantizar la seguridad de las personas migrantes forzadas.
\end{abstract}

Palabras clave: Migración forzada, Desplazamiento forzado interno, Asilo, Violencia, Ciudad Juárez

FROM INTERNALLY DISPLACED PERSONS TO ASYLUM SEEKERS. THE COMPLEXITY OF THE PHENOMENON OF VIOLENT Migration In CiUdAd JuAREZ, CHIHUAHUA, MEXICO

\begin{abstract}
The purpose of this article is to analyze the transitability experienced by forced migrants, through migratory categories such as "internally forcibly displaced" or "applicants for international protection" through refuge, asylum or forced return. For this purpose, the information from the Survey of Displaced Mexicans Seeking Asylum (ENMEDESA), conducted in 2019 in Ciudad Juarez, Chihuahua, is used as a case study, from whose analysis it is concluded that the current contexts of forced mobility, derived from violence, surpass the migratory categories, insufficient to explain and attend to this phenomenon, evidencing its complexity and multidimensionality, where the subjects acquire migratory profiles with a high degree of transitability which blurs the responsibility of States to attend to, protect and guarantee the safety of forced migrants.
\end{abstract}

Keywords: Forced migration, Forced internal displacement, Asylum, Violence, Ciudad Juárez

\section{DE DÉPLACÉS INTERNES À DEMANDEURS D’ ASILE. LA COMPLEXITÉ DU PHÉNOMĖNE MIGRATOIRE À CAUSE DE LA VIOLENCE À CIUDAD JuÁreZ, CHIHUAHUA, MÉXICO}

Résumé

Cet article a comme but celui d'analyser la marchabilité que les migrants forcés expérimentent à travers les catégories migratoires comme « déplacés forcés internes » ou « demandeurs de protection internationale »à travers le refuge, l'asile ou le retour forcé. Pour cela, on utilise comme cas d'étude l'information de l' Encuesta de Mexicanos Desplazados Solicitantes de Asilo (ENMEDESA), réalisée en 2019 à Ciudad Juárez, Chihuahua, analyse à partir de laquelle on conclue que les contextes actuels de mobilité forcée, dérivés de la violence, dépassent les catégories migratoires insuffisantes pour expliquer et prêter attention à ce phénomène, en mettant en évidence sa complexité et multi-

* Doctora en Estudios de Migración; coordinadora de la Especialidad en Migración Internacional de El Colegio de la Frontera Norte, México.

Clivajes. Revista de Ciencias Sociales (ISSN: 2395-9495), Año VIII, Núm. 15, enero-junio, 2021 Instituto de Investigaciones Histórico-Sociales, Universidad Veracruzana, México 
dimensionalité où les sujets acquièrent des profils migratoires avec un grand degré de marchabilité qui esquisse la responsabilité des États pour prêter attention, protéger et garantir la sécurité des personnes migrantes forcées.

Mots clés : Migration forcée, Déplacement forcé interne, Asile, Violence, Ciudad Juárez

\section{INTRODUCCIÓN}

Las migraciones forzadas se han convertido en uno de los flujos migratorios cada vez más visibles en el mundo, debido a su volumen, características y contextos/motivos de salida. Una de las particularidades de esta movilidad es que desde los estudios de migración se han fundamentado, particularmente, a través de las escalas de voluntariedad ante la toma de decisión de emigrar, lo que la diferencia de otras movilidades, como es la tradicional migración económica. En este sentido, Castles (2003) y Herrera (2006) señalan que la crisis global de migración por la que se atraviesa hace cada vez más complejo diferenciar entre las migraciones forzadas y las voluntarias, por lo que es necesario profundizar en las causas, las dimensiones y los contextos de salida, puesto que esta crisis global se ha caracterizado por crecientes flujos migratorios motivados por violencia, los cuales han sido observados en diversas latitudes del continente americano, oriente medio, el norte y centro de África, entre otras.

Entre las migraciones forzadas, caracterizadas por la involuntariedad, se han identificado flujos de refugiados, desplazados internos y apátridas. Según el Informe sobre las Migraciones en el Mundo, de la Organización Internacional de las Migraciones (OIM) 2020, hay evidencia de que actualmente se cuentan más de 25.9 millones de personas en condición de refugio, 41.3 millones de desplazados internos por motivos de violencia y conflictos armados, y 3.9 millones de personas apátridas. A través de diversas investigaciones, se ha podido demostrar la existencia de canales de expulsión específicos que originan este tipo de flujos forzados, como son las expresiones de violencia generalizada, la presencia de grupos del crimen organizado, la violación sistémica de los derechos humanos, la generación de políticas migratorias restrictivas, el desarrollo de megaproyectos, así como persecuciones políticas y religiosas (Arango, 2003 y Castles, 2003).

Sin embargo, a pesar del esfuerzo realizado para la generación de categorías migratorias de corte político, administrativo y jurídico, muchas de éstas surgidas desde instrumentos internacionales y que nos han permitido aproximarnos al estudio de las migraciones forzadas, hoy en día nos limitan para explicar parte de la movilidad humana 
que se gesta ante los contextos de violencia, cada vez más agudos. Se ha identificado una transitabilidad de categorías migratorias en un mismo individuo. Para fines de la investigación de que da cuenta este artículo, nos hemos centrado en el desplazamiento forzado interno y los solicitantes de asilo, reconociendo al desplazamiento forzado interno como una categoría que se ha acuñado internacionalmente para hacer referencia a las personas o grupos de personas que se han visto obligadas a huir de su residencia habitual por motivos o efectos de conflictos armados, violencia generalizada, violación a sus derechos humanos, desastres naturales o persecuciones, sean políticas o religiosas. Este tipo de movilidades se caracteriza por que las personas no cruzan un límite políticoadministrativo, por lo que los movimientos ocurren dentro de un mismo Estado-nación, ya sea de manera individual, como tienden a invisibilizarse, o de manera masiva. En el caso del asilo, es una categoría que garantiza la protección por parte de un Estado hacia un extranjero en su territorio, contra el ejercicio de la jurisdicción del Estado de origen, sustentados en el principio de non refoulement (OIM, 2006).

Centrándonos en el caso mexicano, se puede identificar que el inicio de la guerra contra el crimen organizado, durante el último quinquenio de la década de los 2000, dio origen a un incremento exponencial de los índices delictivos en el centro occidente y norte del país, ocasionando desplazamientos forzados internos en entidades federativas como Guerrero, Michoacán, Chihuahua, Tamaulipas, entre otras. Sin embargo, se reconoce que, al no existir un auto de ley para el reconocimiento de la figura legal del desplazado forzado interno, ni un marco jurídico apropiado que permita atender sus necesidades y garantizar sus derechos humanos, estas personas toman la decisión de buscar protección internacional en Estados Unidos, solicitando un asilo.

Ante dicho contexto, este artículo pretende centrarse en el análisis de la transitabilidad de categorías migratorias forzadas, a partir del caso de estudio de desplazados forzados internos, que huyeron de su residencia habitual por motivos de violencia, presencia del crimen organizado e inseguridad pública; que llegaron a Ciudad Juárez, México, para solicitar protección internacional a través del asilo, lo que los vuelve sujetos que experimentan el tránsito a través de diversas categorías migratorias. El texto se divide en tres partes; la primera plantea un análisis de las categorías migratorias, centrándose en el desplazamiento forzado interno y los solicitantes de protección internacional; en la segunda se desarrolla un marco contextual sobre el impacto de la violencia en la movilidad humana, destacándose el caso mexicano a partir del contexto de violencia derivada de la guerra contra el crimen organizado; en la tercera se analiza el 
caso de los desplazados en Ciudad Juárez, a la luz de los resultados de la Encuesta de Mexicanos Desplazados Solicitantes de Asilo (ENMEDESA).

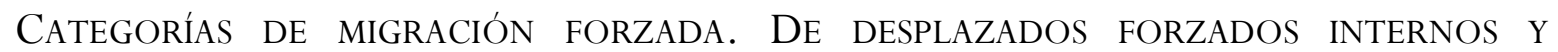
SOLICITANTES DE ASILO

A partir del incremento de las tensiones derivadas de las exclusiones sociopolíticas de diversos Estados, se han presentado variadas expresiones de inestabilidad y violencias, lo cual ha originado movimientos forzados de la población en donde las personas huyen y abandonan sus lugares de residencia habitual en búsqueda de espacios de protección y resguardo (Escobar, 2003). Sin embargo, debido al atributo forzoso de la migración, adherido a determinantes como la subjetividad de medir la voluntariedad de las personas respecto al abandono de sus hogares y la responsabilidad de los Estados, se han generado clasificaciones, tipologías, indicadores y categorías administrativas, políticas y jurídicas para abordar esta movilidad (López et al., 2019).

Algunas de las categorías que se han generado para encasillar los tipos de movilidad forzada, en donde se identifiquen temores fundados respecto a la seguridad de las personas y que las coloque en una situación de riesgo por ser víctimas, son las de desplazados forzados, refugiados, retornados forzados o solicitantes de asilo, las cuales surgen desde instrumentos internacionales que privilegian la protección de las personas y la garantía de sus derechos humanos. Algunos de estos instrumentos se enmarcan dentro del Sistema de Protección Internacional de los Refugiados, tal es el caso de la Convención sobre el Estatuto de Refugiados y Apátridas (1951) ${ }^{1}$, la Declaración de Cartagena sobre los Refugiados (1984) ${ }^{2}$ o los Principios Rectores de los Desplazamientos Internos (1998), ${ }^{3}$ los cuales ayudan a diferenciar a las personas migrantes forzadas a partir de los alcances de la movilidad, es decir, si se mueven dentro de un mismo territorio o cruzan un límite político-administrativo, su reconocimiento legal, así como los factores de expulsión al describirlos de manera amplia.

En el caso de los desplazados internos, el sistema de Naciones Unidas, desde su oficina del Alto Comisionado para Refugiados (ACNUR), presentó, en 1988, los Principios Rectores de los Desplazamientos Internos, como una propuesta no vinculante

\footnotetext{
${ }^{1}$ Convención sobre el Estatuto de Refugiados, de 28 de julio de 1951, convocada por la Asamblea General en su resolución $429(\mathrm{~V})$, de 14 de diciembre de 1950.

${ }^{2}$ Declaración de Cartagena sobre los refugiados, de 22 de noviembre de 1984, OEA/Ser. L/ V/ II. 66, doc. 10, rev. 1

${ }^{3}$ Principios Rectores de los Desplazamiento Internos, de 11 de febrero de 1998, E/CN.4/1998/53/Add.2 
para los Estados, pero que les ayude a entender, atender y proteger a las personas que son desplazadas, a través de la generación de recursos, acciones, estrategias y gestión de la migración, definiendo a los desplazados internos como "las personas o grupos de personas que se han visto forzadas u obligadas a escapar o huir de su lugar de residencia habitual, en particular como resultado o para evitar los efectos de un conflicto armado, de situaciones de violencia generalizada, de violaciones de los derechos humanos o de catástrofes naturales o provocadas por el ser humano, y que no han cruzado una frontera estatal internacionalmente reconocida” (Kälin, 1998).

En este sentido, se puede destacar que el desplazamiento forzado es un proceso que se caracteriza principalmente por no regirse por una racionalidad económica, ya que las personas que se introducen en este proceso de movilidad se guían por una racionalidad subjetiva, en donde la maximización de utilidad monetaria no es la prioridad sino la de resguardar su vida. A nivel mundial se han visibilizado de manera significativa los desplazamientos forzados internos, los cuales se caracterizan, como ya se ha mencionado, por ser una migración involuntaria. Particularmente en el contexto latinoamericano, la mayor proporción de las movilidades forzadas se desarrollan de manera interna debido a conflictos armados u otro tipo de violencias que fungen como factores que obligan a las personas a cambiar su residencia habitual. Uno de los casos más emblemáticos es el de Colombia, donde los conflictos ocasionados por las Fuerzas Armadas Revolucionarias han derivado en el desplazamiento interno de millones de colombianos.

Aunque existe una definición establecida para las personas desplazadas forzadas internas, la realidad es que aún se siguen identificando problemas en diversos países, debido a que, ante la inexistencia de un reconocimiento jurídico y legal, se imposibilita la identificación de los desplazados al no contar con un registro, pero también afecta al no garantizarles los derechos que les corresponden a partir de su categoría migratoria, sobre todo, por la situación de vulnerabilidad en la que se encuentran. Y si bien el ACNUR mantiene una serie de principios rectores que garantizan la seguridad de las personas desplazadas, desde la perspectiva de Cohen (1998), aunque estas personas se encuentren en su propio país, es necesario que sean reconocidas y beneficiadas con los mismos derechos y libertades de cualquier otro connacional que no se haya encontrado en una situación de desplazamiento, adicionando la garantía de cubrir las necesidades especiales que requieren debido a la movilidad que han realizado.

Según datos del Internal Displacement Monitoring Centre, durante 2015 se contabilizaron más de 38 millones de personas desplazadas alrededor del mundo. En México se desplazaron 281400 personas por motivos de conflictos armados y violencia 
generalizada: estos movimientos se pueden visualizar en la figura 1. Un aspecto por señalar es que antes de 2010 México no se caracterizaba por ser un país de desplazamiento forzado interno, pero en la actualidad se encuentra entre los cinco principales países con el mayor número de desplazamientos en América Latina.

Figura 1. Desplazamientos forzados internos en el mundo

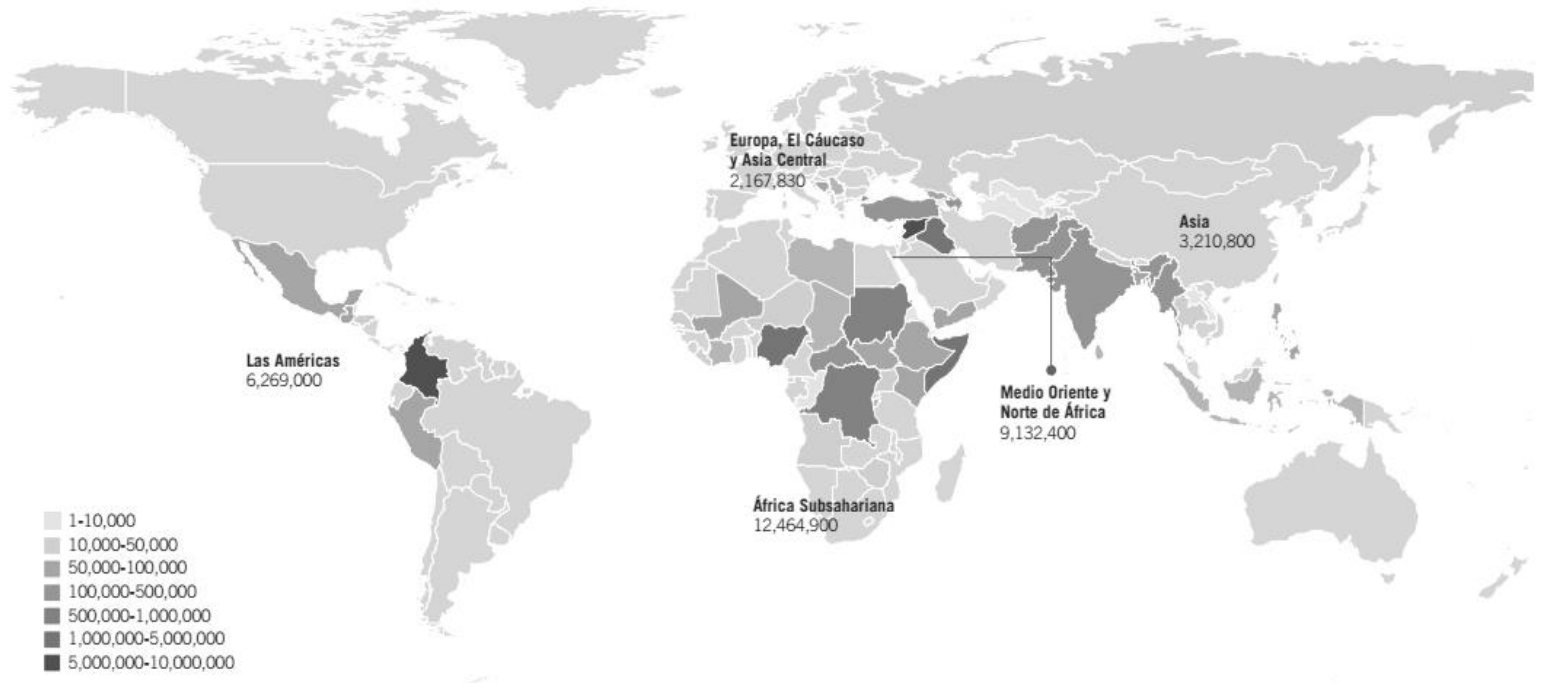

Fuente: Global Overview 2015, del Internal Displacement Monitoring Centre, 2015.

La segunda categoría migratoria considerada y analizada en el presente artículo es la del asilo, la cual también se enmarca en las migraciones forzadas. Esta categoría se fundamenta por la existencia de temores fundados de persecución debido a la raza, religión, nacionalidad o pertenencia a un determinado grupo social, y que la persona se encuentre fuera del país de origen y solicite protección internacional a un Estado-nación diferente al de su nacionalidad (FitzGerald, 2019). En este sentido, el término "asilo" proviene de la palabra griega asylon, que significa "el lugar que no puede ser violado", en donde la principal justificación de la práctica de solicitud de asilo es la protección de la vida humana de las personas, e incluso de sus familiares más cercanos.

El significado contemporáneo que se le ha dado al asilo es el lugar en el cual las personas que son perseguidas puedan encontrar inmunidad y reciban protección contra un peligro inminente. Por otra parte, desde una perspectiva jurídica, el asilo es la protección otorgada por un Estado a la persona que lo ha buscado, esto dentro del mismo territorio del Estado o en algún lugar específico bajo su jurisdicción. El Instituto de 
Derecho Internacional de Bruselas ${ }^{4}$ definió el asilo como "la protección que un Estado otorga a quien lo solicita, ya sea en su territorio o en otro lugar que esté bajo la jurisdicción de alguno de sus órganos” (Rondanini, 2007). En esta misma línea, la OIM define el asilo como la "Protección garantizada por un Estado a un extranjero en su territorio, contra el ejercicio de la jurisdicción del Estado de origen, basada en el principio de non refoulement, que conlleva el ejercicio de determinados derechos reconocidos internacionalmente" (OIM, 2006).

Al igual que el desplazamiento forzado interno, el asilo se ha fundamentado en diversos instrumentos internacionales, tal es el caso de la Declaración Universal de los Derechos Humanos (1948), la Declaración Americana de los Derechos y Deberes del Hombre (1948), así como la Carta de los Derechos Fundamentales de la Unión Europea (2007), por lo que la posibilidad de solicitar asilo se sustenta en el derecho internacional, y aunque una persona tome la decisión de emigrar por tener el temor fundado de que su vida, su seguridad y su libertar se encuentran en peligro por motivos de violencia, conflictos armados o violación a sus derechos humanos, no siempre tienen la posibilidad de adherirse a la protección de sus países, por motivos diversos, como es no confiar en los esquemas de seguridad o protección, o simplemente que su país de residencia no reconocen al desplazamiento forzado como una figura legal, por lo que optan por solicitar protección a otro país bajo la categoría migratoria de refugiado o solicitante de asilo.

Para el caso del sistema de inmigración de Estados Unidos, tanto el asilo como el refugio son estatus prioritarios, esto estipulado desde su Código a través del Título 8 de Inmigración y naturalización y de la política de inmigración, además de los tratados y convenios internacionales a los que se ha adscrito. En este sentido, se considera a los refugiados como personas que están fuera de sus países, que no pueden o no están dispuestos a volver ahí, porque temen daños personales graves; entre los motivos por los cuales no puede regresar a sus países, ese cuentan persecución o temor fundado por motivos de raza, religión, nacionalidad o pertenencia a un determinado grupo social u opinión política. Por otra parte, las personas solicitantes de asilo o con estatus de asilo cumplen con la definición de refugiados, pero éstos ya están presentes en Estados Unidos o se encuentran buscando la admisión en algún puerto de entrada. Todas las personas pueden solicitar asilo en Estados Unidos sin importar su país de origen o estatus migratorio, es decir, personas que incluso se encuentren de manera indocumentado o

\footnotetext{
${ }^{4}$ Reunión de 1950.
} 
irregular dentro de Estados Unidos, por menos de un año, podrían ser elegibles para realizar una solicitud de asilo (DHS, 2016).

Un elemento fundamental en los procesos del reconocimiento de la categoría migratoria de asilo es el establecimiento y declaración del temor fundado. Gortázar (1997) establece que el fundamento del temor de las personas solicitantes de las condiciones de asilo o refugio es un elemento clave, puesto que no puede depender únicamente del estado anímico de las personas solicitantes sino de una situación objetiva para determinar la existencia de temores fundados razonables. En este sentido, las personas que solicitan asilo ante las autoridades de Estados Unidos deben de llevar pruebas físicas que demuestren algún temor fundado; posterior a eso, deberán de llenar el Formulario I-589, con la finalidad de comenzar con la petición del asilo. En muchos de los casos, y a pesar de que los solicitantes cuenten con las pruebas y cumplan con los requisitos, no acceden a la condición de asilados. Se estima que sólo el 13.7\% de los solicitantes logran obtenerlo. En el Cuadro 1 se puede identificar que, de las más de 200 mil solicitudes de asilo recibidas en el año fiscal de 2019, por parte de las autoridades de inmigración de Estados Unidos, únicamente 27643 tuvieron una resolución positiva.

Cuadro 1. Casos de petición y resolución de la condición de asilo en Estados Unidos, años fiscales de 2017 a 2019

\begin{tabular}{lccc}
\hline \multicolumn{4}{c}{ Casos recibidos de petición de asilo } \\
\hline País & $\mathbf{2 0 1 7}$ & $\mathbf{2 0 1 8}$ & $\mathbf{2 0 1 9}$ \\
\hline Total & 144662 & 163271 & 201572 \\
Guatemala & $16.5 \%$ & $16.5 \%$ & $19.6 \%$ \\
Honduras & $14.7 \%$ & $13.5 \%$ & $15.0 \%$ \\
México & $15.5 \%$ & $15.2 \%$ & $14.4 \%$ \\
El Salvador & $26.3 \%$ & $19.7 \%$ & $14.1 \%$ \\
Venezuela & $0.3 \%$ & $3.2 \%$ & $5.5 \%$ \\
India & $3.3 \%$ & $4.8 \%$ & $5.2 \%$ \\
China & $4.4 \%$ & $5.0 \%$ & $3.2 \%$ \\
Cuba & $0.4 \%$ & $0.7 \%$ & $2.6 \%$ \\
Ecuador & $2.8 \%$ & $2.5 \%$ & $2.1 \%$ \\
Nicaragua & $0.4 \%$ & $0.5 \%$ & $1.8 \%$ \\
Otros países & $15.4 \%$ & $18.5 \%$ & $16.3 \%$ \\
\hline
\end{tabular}

\begin{tabular}{lccc}
\multicolumn{4}{c}{ Casos afirmativos de asilo } \\
País & $\mathbf{2 0 1 7}$ & $\mathbf{2 0 1 8}$ & $\mathbf{2 0 1 9}$ \\
\hline Total & 15639 & 24382 & 27643 \\
Venezuela & $3.1 \%$ & $23.5 \%$ & $22.9 \%$ \\
China & $18.0 \%$ & $15.4 \%$ & $14.6 \%$
\end{tabular}




$\begin{array}{lccc}\text { Egipto } & 6.5 \% & 5.8 \% & 7.8 \% \\ \text { Turquía } & 0.1 \% & 1.9 \% & 6.3 \% \\ \text { Rusia } & 1.8 \% & 3.1 \% & 4.0 \% \\ \text { Guatemala } & 12.8 \% & 5.4 \% & 3.8 \% \\ \text { El Salvador } & 13.5 \% & 4.7 \% & 3.2 \% \\ \text { México } & 3.1 \% & 2.9 \% & 2.9 \% \\ \text { Nigeria } & 0.8 \% & 1.9 \% & 2.8 \% \\ \text { Honduras } & 6.9 \% & 3.4 \% & 1.9 \% \\ \text { Otros países } & 33.4 \% & 32.1 \% & 29.8 \% \\ \text { Fuente: Elaboración propia con base en datos de U.S. Department of Homeland Security, 2020. }\end{array}$

Para el caso de los mexicanos solicitantes de asilo, las solicitudes aceptadas se han incrementado de manera exponencial, ya que del año fiscal 2010 se aceptaron 132, para el 2015, 667, y para 2019, 791, lo que indica un crecimiento de 599\% y de 2010 a 2019 el porcentaje de aceptación fue del $2.6 \%$.

Un aspecto importante a considerar, es que si bien, a través del presente artículo se hace referencia a cómo se han definido las categorías migratorias a partir de los instrumentos internacionales y del marco normativo de Estados Unidos, la realidad es que estas definiciones y sobre todo los procesos de reconocimiento pueden variar según la normatividad establecida por cada Estado; por ejemplo, el asilo en México es considerado más de carácter político, puesto que se reconoce como asilo al extranjero que vea peligrar su vida, libertad o seguridad por cuestiones políticas y no cuente con protección de su país de origen. Sin embargo, uno de los puntos centrales es que, independientemente de la definición de la categoría migratoria por cada uno de los Estados, tiene que garantizarse el derecho de asilo a las personas o su reconocimiento como desplazados forzados internos o solicitantes de protección internacional.

\section{MOVILIDAD FORZADA Y CONTEXTO DE VIOLENCIA EN MÉXICO}

Desde las ciencias sociales, los enfoques teóricos y analíticos tradicionales para abordar el fenómeno migratorio se han sustentado en relacionar la movilidad con factores y determinantes económicos, destacando que las migraciones humanas obedecen a la dinámica de los mercados laborales, la relación salarial, la demanda de mano de obra y la maximización de utilidades de las personas (Arango, 2003 y Lee, 1966). No obstante, se han identificado otros determinantes que influyen en la conformación de procesos migratorios, los cuales no se encuentran subordinados a elementos de carácter económico. 
Incluso Ravenstein, quien mencionaba que la migración era producto de motivaciones económicas, no dejaba de destacar que otros elementos, como "las malas leyes u opresivas, los impuestos elevados, un clima poco atractivo, un entorno social desagradable e incluso la coacción han producido corrientes migratoria” (Ravenstein, 1885, p. 12), por lo cual estas afirmaciones pueden ser las que en la actualidad den luz a la explicación sobre las nuevas dinámicas que se presentan en la migración, no necesariamente motivadas por razones económicas.

Morrison (1993), Sirkeci (2005), Alvarado y Massey (2010), entre otros, han realizado investigaciones donde analizan cómo las violencias, expresadas a través de diversos procesos, se convierten en un determinante para la migración, la cual ya no es explicada por las perspectivas racionalistas o los enfoques economicistas de costo-beneficio que priman en los entramados teóricos clásicos y neoclásicos de la migración internacional. En este sentido, se destaca que, durante las últimas décadas, la relación entre migración y violencia ha sido parte fundamental en el estudio de la movilidad humana, lo cual se ha expresado a través de investigaciones situadas que identifican, analizan y reflexionan cómo las violencias, la presencia del crimen organizado, la violación sistemática de derechos humanos o contextos en donde se desarrollan actividades relacionadas con el narcotráfico inciden de manera directa en la decisión de migrar, una decisión que no tiene como objetivo obtener un mayor beneficio económico, sino proteger la vida y garantizar la seguridad y libertad de las personas.

De manera precisa se pueden identificar investigaciones muy particulares que analizan el impacto que han tenido algunas expresiones de violencia en la movilidad humana. Morrison (1993) identifica que la violencia tiene un papel clave en la decisión a emigrar por parte de las familias, señalando que la probabilidad de migrar se incrementa de manera proporcional ante el aumento de los niveles de violencia, pero también de los contextos de crisis políticas, particularmente en los países pertenecientes al llamado Triángulo Norte; por ejemplo, en Guatemala se destaca que el desplazamiento forzado interno ha sido la respuesta a los procesos de violencia. Bohra-Misha y Massey (2011) encuentran que la violencia tiene una relación directa con la migración, cuya movilidad puede trascender fronteras o dentro de un mismo territorio, puesto que los episodios violentos tienen un impacto en el bienestar de las personas, destacando una relación negativa, puesto que a medida que los niveles de violencia incrementan los niveles de bienestar disminuyen. Un aporte importante de los autores es que la migración se producirá a partir de un nivel específico de violencia, es decir, la existencia de un umbral de violencia que puede cambiar dependiendo de los contextos geoespaciales. 
Por otra parte, se puede destacar que no únicamente la violencia o contextos específicos de ésta tienen un impacto en la migración, sino también acciones o estrategias dirigidas a combatirla. Miron (2001) argumenta que la aplicación de políticas antidrogas impacta, en la mayoría de las ocasiones, en el crecimiento de los índices delictivos debido a la resistencia de los grupos del crimen organizado que desarrollan actividades ilícitas, lo cual da como resultado un crecimiento de la inseguridad y la violencia, y pone a la población en riesgo, por lo que el desplazamiento forzado interno o la migración por violencia es la respuesta ante estos escenarios. En esta misma línea, Alvarado y Massey (2010), Wood et. al. (2010), Ramírez y Meza (2012) y Barrios (2016) señalan que la violencia provocada por el narcotráfico o por el enfrentamientos entre los grupos delincuenciales motiva el desarrollo de migraciones forzadas, aunque también reconocen las dificultades teóricas y metodológicas para establecer dicha relación; de ahí que mediante sus trabajos de investigación exploren aproximaciones estadísticas haciendo uso de indicadores particulares, como el de homicidio, para evaluar el impacto que tiene la violencia en los desplazamientos, llegando a identificar que las personas se mueven, regularmente, a localidades con menores índices de delincuencia.

Siguiendo la hipótesis planteada por Miron (2001), en México se identifica un contexto de alta violencia que ha sido asociado al desplazamiento forzado interno de familias del centro-occidente y norte del país. Si bien la situación de violencia que aqueja a gran parte de las entidades federativas es un problema transcendental, en el año 2006, con un nuevo gobierno, se estableció un mecanismo de seguridad, a través de la implementación de la estrategia nacional de seguridad, con el fin de combatir el narcotráfico y el crimen organizado (Chabat, 2010). La ejecución de tal estrategia se llevó a cabo a finales de 2007. El punto nodal de este programa contra el crimen organizado era establecer operativos para "recuperar la fortaleza del Estado y la seguridad en la convivencia social mediante el combate frontal y eficaz al narcotráfico y a otras expresiones del crimen organizado”. Dichos operativos comenzaron en el estado de Michoacán y posteriormente en otras entidades federativas del país (PND, 2007-2012). Según información del Censo Nacional de Gobierno, Seguridad Pública y Sistema Penitenciario Estatales del año 2014, Michoacán y Guerrero estaban entre las entidades federativas con mayor violencia e inseguridad pública, además de ocupar los primeros lugares a nivel nacional por el número de homicidios, con tasas mayores a 70 homicidios por cada 100 000 habitantes. En este sentido, investigaciones realizadas por la Comisión Mexicana de Defensa y Promoción de los Derechos Humanos mencionan que la presencia de grupos de delincuencia organizada, como La Familia Michoacana y los Caballeros Templarios, han 
provocado la muerte de decenas de personas, así como el desplazamiento forzado de varias familias (IGI-MEX, 2016).

Así como el caso de los michoacanos, Velásquez (2012) y Barrios (2016) identifican que este mismo contexto de violencia orilló a cientos de miles de juarenses a desplazarse a comunidades del centro y sur del país, particularmente a entidades federativas como Veracruz, Durango y Coahuila, pero muchos, al no encontrar contextos de protección por parte de los Estados, tomaron la decisión de solicitar protección internacional a este país mediante el asilo; sin embargo, tal como se señaló anteriormente, la tasa de aceptación de asilo para mexicanos es menor al 3\%, lo que los convierte, después de la negación por parte del gobierno estadounidense, en repatriados mexicanos, y al llegar al país se encuentran sin ningún tipo de protección por su condición de vulnerabilidad, puesto que al cruzar un límite político-administrativo ya no pueden ser considerados desplazados, aunque los motivos de salida sigan presentes, lo que les impide regresar a sus comunidades de origen. Así como este caso, a partir de 2006, se han replicado muchos otros a lo largo de los diferentes estados de la República mexicana, evidenciando la complejidad para analizar estas situaciones de movilidad forzada a través de las categorías migratorias existentes.

\section{DE DESPLAZADOS INTERNOS EN CIUDAD JUÁREZ A SOLICITANTES DE ASILO}

Durante 2019, en el marco de una crisis migratoria en la frontera norte de México por la llegada de miles de migrantes extranjeros solicitantes de protección internacional, muchos de ellos organizados a través de caravanas, Ciudad Juárez fue el epicentro para la confluencia de otros flujos migratorios forzados, tal es el caso de los desplazados con cruce de frontera internacional (solicitantes de la condición de refugio y asilo), los desplazamientos de intersección (deportación/repatriación) y los desplazados forzados internos, tal como los identifican López et. al. (2019). En el caso de Ciudad Juárez, esta situación se visibilizó de manera particular, puesto que en la última década el fenómeno migratorio no había tenido una presencia significativa, por lo que al comenzar a identificar a miles de migrantes y no contar con la infraestructura ni recursos para su atención y regulación, se suscitó una especie de crisis de atención a personas en situación de movilidad.

Para agosto de 2019, Ciudad Juárez se había convertido en la principal ciudad fronteriza con mayor concentración de migrantes internacionales, mayoritariamente centroamericanos y caribeños. Aunado a esto, en octubre del mismo año se comenzó a 
identificar el arribo de migrantes mexicanos, que al igual que los extranjeros llegaban a la ciudad para iniciar un proceso de petición de asilo. Al cabo de dos meses ya se contabilizaban al menos 3000 mexicanos asentados en las inmediaciones de los puentes internacionales que conectaban a Ciudad Juárez y El Paso Texas, con la finalidad de dar inicio a su proceso de solicitud de protección internacional a Estados Unidos. Al momento de analizar quiénes eran estos mexicanos y por qué estaban llegando a la ciudad, se identificó que eran desplazados forzados internos, y que al no encontrar protección por parte del Estado mexicano identificaron que otra posibilidad de protección era buscarla en otro país solicitando la condición de asilo (Barrios, López y Rubio, 2020). Esta situación evidencia cómo estos migrantes forzados pueden transitar fácilmente de una categoría migratoria a otra, ya que la realidad del fenómeno migratorio actual es más compleja y los marcos conceptuales, administrativos y jurídicos, insuficientes para explicar y atender a las personas migrantes forzadas.

Con la finalidad de conocer de manera precisa características de la población, las causas y contextos de salida, así como sus expectativas respecto al asilo, se realizó la Encuesta de Mexicanos Desplazados Solicitantes de Asilo (ENMEDESA). Esta encuesta formó parte de un estudio más amplio que se denominó: "Diagnóstico sobre el contexto migratorio en Ciudad Juárez 2018-2019: dimensión y caracterización de migrantes internacionales y nacionales solicitantes de asilo a Estados Unidos”. Este estudio fue un esfuerzo realizado por El Grupo Interdisciplinario en Temas Migratorios (GITM) conformado por investigadoras e investigadores de El Colegio de Chihuahua, El Colegio de la Frontera Norte, la Universidad Autónoma de Ciudad Juárez y la Universidad Autónoma de Chihuahua.

Particularmente, la ENMEDESA fue estructurada en un formato de aplicación que consistió en un cuestionario que permitiera emplear las preguntas a un informante clave, para estar en condiciones de captar las variables incluidas no solamente de esa persona, sino también del resto de miembros de la familia, cuando fuera el caso. La ENMEDESA es parte de un estudio de corte transversal; se aplicó en los tres puntos de concentración y espera de mexicanos desplazados internos aspirantes a solicitar asilo. En un primer momento, a finales de octubre de 2019, se trabajó en los puentes Santa Fe y Zaragoza, mientras que en el Puente Libre se realizó hasta los primeros días del mes de noviembre de 2019. La estrategia metodológica a seguir fue un ejercicio que permitiera registrar y entrevistar a todas las personas que se encontraran en el punto de aplicación en la fecha indicada para cada lugar. Esto quiere decir que se entrevistó a las personas que se 
encontraban en cada uno de los puentes, con el fin de tener una fotografía lo más amplia posible del fenómeno, alcanzando a captar información de 932 personas desplazadas.

Las principales características identificadas a través de la encuesta fueron las sociodemográficas y permitieron conocer la estructura por edad y sexo de la población desplazada interna. Al respecto, se puede destacar que el 46\% de la población fue de hombres, mientras que el 54\% fue de mujeres. Por otra parte, si se analiza la estructura por grandes grupos de edad, es importante decir que casi la mitad (48\%) de las personas desplazadas fueron menores de edad (0-17 años), de los cuales 34\% eran menores de 10 años; luego, un $16 \%$ tenía entre 18 y 24 años; otro $20 \%$ se encontraba en el grupo etario 25 a 34 años, y el restante 16\% tenía 35 años o más. Este comportamiento demuestra que la población desplazada que se encontró en Ciudad Juárez es muy joven y que la movilidad forzada se desarrolló de manera colectiva a través de grupos familiares, en donde al menos se encontraban dos menores de edad por unidad familiar (Véase Gráfica 1).

\section{Gráfica 1.}

Estructura por edad y sexo de la población desplazada solicitante de asilo. Ciudad Juárez, 2019

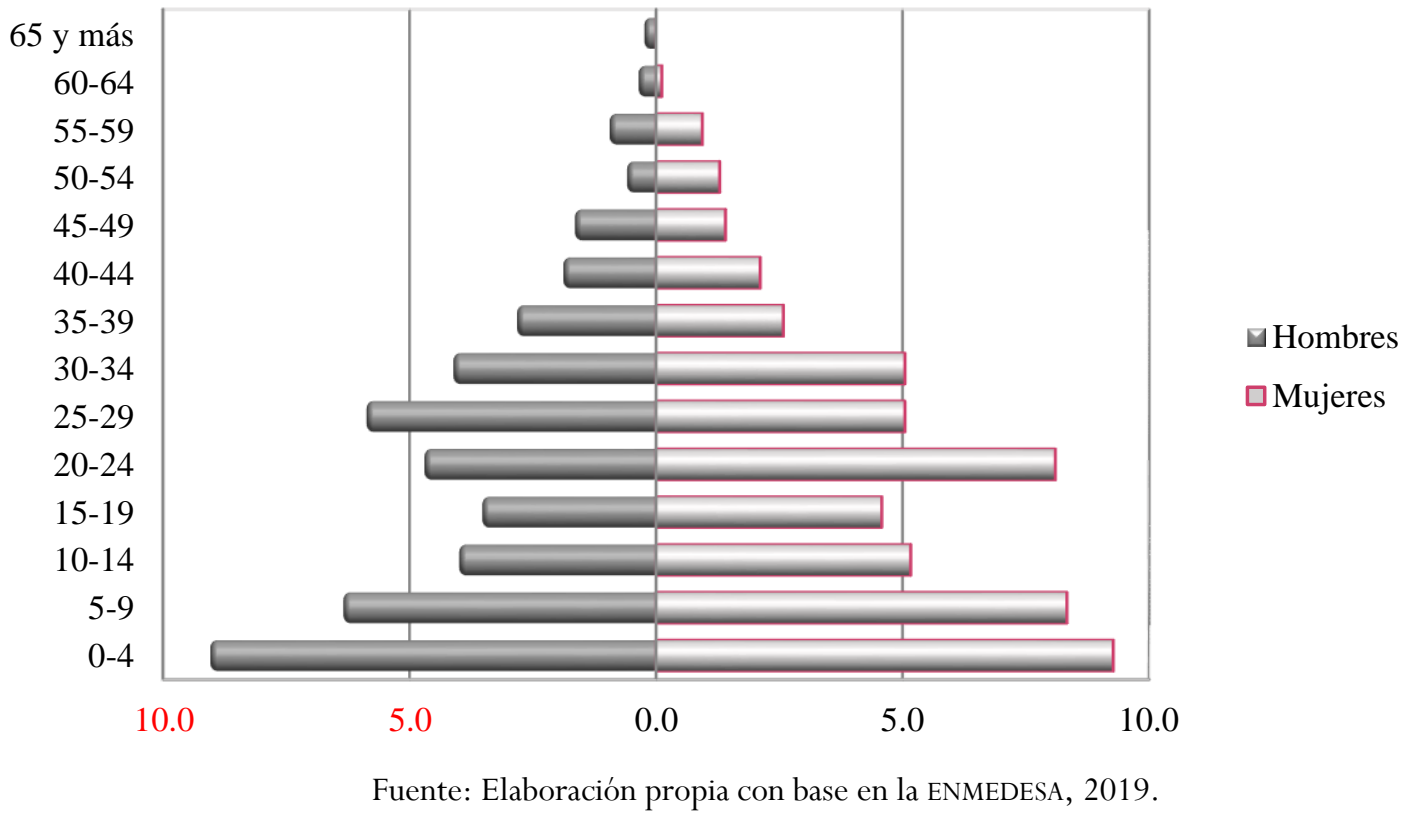

La presencia tan alta de menores también alude a mayores contextos de vulnerabilidad, puesto que las familias salen de sus lugares de residencia para proteger y cuidar el bienestar de sus hijos, quienes en muchos casos se ven afectados por las situaciones de exclusión social motivadas por conflictos armados, como se ha dado por décadas en el contexto colombiano (Patiño y Herrán, 2012). 
Otras de las características sociodemográficas que se analizaron fueron el estado civil (véase Cuadro 2), la identificación del estado de procedencia (véase Gráfica 2) y la actividad que desarrollaban antes de salir de su lugar de residencia habitual (véase Cuadro 3). El estado civil únicamente fue registrado para la población mayor a 15 años, de los cuales el $67 \%$ se encontraban en pareja; es decir, el 50\% se encontraban casados y el $17 \%$ en unión libre. Por otra parte, cerca del 26\% estaban solteros y, en menor medida, separados, viudos o divorciados.

\section{Cuadro 2.}

Estado civil de la población de 15 años y más desplazada interna solicitante de asilo.

Ciudad Juárez, 2019

\begin{tabular}{lc}
\hline Condición civil & $\mathbf{\%}$ \\
\hline Casado (a) & 50.0 \\
Soltero (a) & 25.8 \\
Unión libre & 16.7 \\
Divorciado (a) & 1.0 \\
Viudo (a) & 2.4 \\
Separado (a) & 4.2 \\
Total & $\mathbf{1 0 0 . 0}$ \\
\hline
\end{tabular}

Respecto a los lugares de residencia de los mexicanos desplazados, se logró observar que provenían de las siguientes entidades federativas: el 56.7\% de Michoacán, el 18.1\% de Zacatecas, el $17.1 \%$ de Guerrero y el 3.5\% de Chiapas. De las personas desplazadas forzadas de Michoacán, se identifican comunidades muy particulares, cerca del 21.1\% salió de Ciudad Hidalgo, el 17.5\% de Los Reyes y 12.5\% de Apatzingán. El desplazamiento forzado de michoacanos es un caso particular, puesto la entidad desde el 2008 ha atravesado fuertes contextos de violencia y enfrentamientos entre grupos del crimen organizado, autoridades de seguridad y paramilitares, por lo que solicitar asilo a Estados Unidos se convierte en una estrategia para resguardar la vida. Sin embargo, también se reconoce que la petición de protección internacional no sólo obedece a los episodios violentos, sino también a la construcción de las redes sociales trasnacionales de las comunidades michoacanas, ya que Michoacán es una de las entidades federativas con 
mayor tradición migratoria hacia Estados Unidos, por lo que cerca del $87 \%{ }^{5}$ de los hogares michoacanos cuentan con un familiar o conocido en Estados Unidos.

\section{Gráfica 2.}

Entidad federativa de procedencia de los mexicanos desplazados solicitantes de asilo.

Ciudad Juárez, 2019

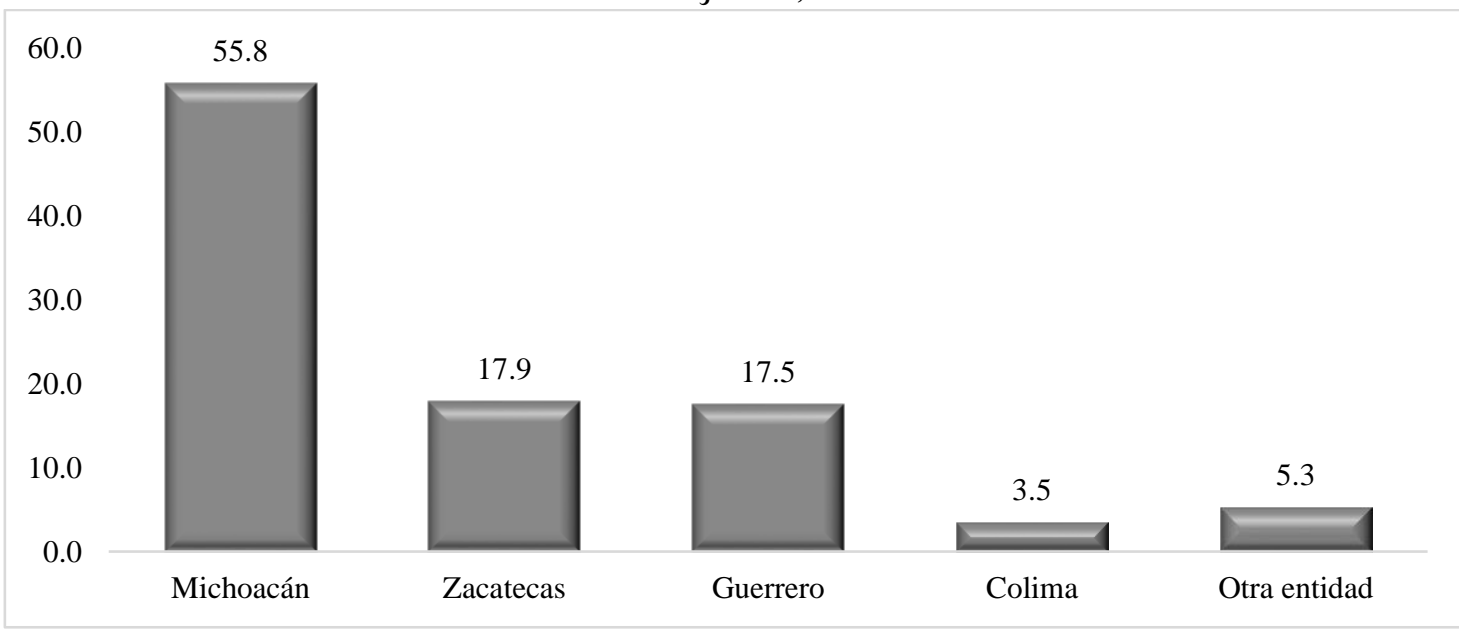

Fuente: Elaboración propia con base en la ENMEDESA, 2019.

La presencia de michoacanos desplazados internos, que desean solicitar asilo a través de las ciudades fronterizas del norte de México, no significa un fenómeno migratorio nuevo, pero, en el contexto de violencia que comenzó a agudizarse en el año 2010, la presencia de familias michoacanas en las ciudades de la frontera norte empezó a visibilizarse de manera particular a principios de 2013, según información de asociaciones de la Coalición Pro Defensa del Migrante de Baja California, a las cuales llegaban las familias antes de acudir a algún puerto de entrada de Estados Unidos. La mayoría de las personas que van en busca de asilo manifiesta que la principal razón por la que acude es el agudo clima de violencia en sus comunidades, donde los gobiernos locales ni estatales le garantizan el derecho a la seguridad. Se estima que, de 2013 a finales de 2014, en promedio acudieron doscientas personas diarias a la garita de San Ysidro, en Tijuana, Baja California, para realizar la petición correspondiente, armadas de cartas y documentos testimoniales sobre el clima de violencia que vivían en el estado de Michoacán para demostrar el temor fundado del que ya se expuso anteriormente (Moreno et. al, $2015 \mathrm{y}$ Avendaño, 2016).

${ }^{5}$ Información obtenida de la base de datos construida por el Mexican Migration Project. 
Esta conformación de procesos migratorios forzados contemporáneos en México, que desembocan en varias de las ciudades fronterizas del norte, tiene una particularidad que los distingue de otros flujos tradicionales, y es que el motivo de salida no se encuentra ligado a actividades económicas, tal como ya se manifestó. En este sentido, en el Cuadro 3 se muestra la relación de actividades a las que se dedicaban estos desplazados internos, captados en Ciudad Juárez, antes de tomar la decisión de salir de sus comunidades de residencia. Se destaca que el 61.2\% se encontraba trabajando, el 20.5\% se dedicaba a los quehaceres del hogar, el $11.8 \%$ estaba estudiando, y únicamente el 1.4\% se encontraba buscando trabajo, lo que evidencia que la conformación de estos flujos migratorios no se relaciona con la necesidad de trabajo o razones de carácter económico.

\section{Cuadro 3.}

Actividad $^{6}$ a la que se dedicaban los mexicanos desplazados solicitantes de asilo. Ciudad Juárez, 2019

\begin{tabular}{lc}
\multicolumn{1}{c}{ Actividad } & Porcentaje (\%) \\
\hline Trabajaba & 61.2 \\
Se dedicaba a los quehaceres del hogar & 20.5 \\
Era estudiante & 11.8 \\
No estudiaba ni trabajaba & 3.0 \\
Estaba Inhabilitado & 1.6 \\
Buscó trabajo & 1.4 \\
Es jubilado (a) & .6 \\
\hline \multicolumn{2}{c}{ Fuente: Elaboración propia con base en la ENMEDESA, 2019.}
\end{tabular}

Además de las características sociodemográficas, se exploraron algunos otros aspectos relacionados con los motivos de salida y el conocimiento sobre el proceso de asilo. En el Cuadro 4 se muestran las dos principales razones por las cuales los desplazados tomaron la decisión de salir de sus lugares de residencia habitual, en donde se identifica que el 93\% de las personas encuestadas manifestaron que la principal razón se encontraba asociada a expresiones de violencia, es decir, el $43.8 \%$ por inseguridad, particularmente por estar expuestos a contextos de violencia; el $28 \%$ por violencia derivada del narcotráfico; el 13.6\% por haber recibido de manera directa amenazas, ser extorsionadas o víctimas de cobro de piso, y el 4.5\% por persecución política. La segunda razón de salida registrada también se caracterizó por las condiciones adversas de violencia, ya que

${ }^{6}$ Está variable únicamente fue captada para la población mayor de 15 años.

Clivajes. Revista de Ciencias Sociales (ISSN: 2395-9495), Año VIII, Núm. 15, enero-junio, 2021 Instituto de Investigaciones Histórico-Sociales, Universidad Veracruzana, México 
el 82.2\% manifestó haber salido por inseguridad, violencia del narcotráfico, amenazas, violencia intrafamiliar o por haber sido secuestrado.

\section{Cuadro 4.}

Razones por las cuales abandonaron sus lugares de residencia habitual los mexicanos desplazados solicitantes de asilo. Ciudad Juárez, 2019

\begin{tabular}{llc}
\hline Razones & Porcentaje (\%) \\
\hline & Inseguridad (robo, delincuencia) & 43.8 \\
& Violencia por narcotráfico & 28.1 \\
& Amenazas / extorsión / cobro de piso & 13.6 \\
& Persecución política & 4.5 \\
Razón 1 & Malas condiciones de empleo / desempleo & 4.5 \\
& Violencia intrafamiliar & 2.9 \\
& Pobreza & 1.7 \\
& Discriminación & 0.4 \\
& Secuestro & 0.4 \\
& Amenazas/extorsión / cobro de piso & 28.9 \\
& Violencia por narcotráfico & 28.4 \\
& Inseguridad (robo, delincuencia) & 16.4 \\
& Malas condiciones de empleo / desempleo & 10.9 \\
Pobreza & 6.5 \\
& Secuestro & 4.0 \\
Persecución política & 3.0 \\
Violencia intrafamiliar & 1.5 \\
Discriminación & .5 \\
\hline Fuente: Elaboración propia con base en la ENMEDESA, 2019.
\end{tabular}

Este contexto de razones de salida señaladas por el flujo migratorio, en donde se les preguntó por las dos principales, demuestran la presencia de la cualidad de lo forzoso ante la toma de decisión de salida, puesto que no únicamente se refiere a la voluntad o involuntariedad del migrante, sino que se vincula también con problemas estructurales de expulsión, tal es el caso de la violencia generada por la presencia y desarrollo de actividades vinculadas al narcotráfico en México, lo cual pone a las personas en situaciones de vulnerabilidad. En este sentido, González (2002) argumenta que la condición de desplazamiento forzado puede ser utilizada por actores armados, que lo pueden manipular como control territorial de ciertas comunidades, como corredores estratégicos, ya sea de armas o sustancias ilícitas, y esté podría ser el caso de muchas zonas de conflicto en México.

Otro de los aspectos que se rescataron a través de la encuesta es si las personas habían buscado apoyo de las autoridades de sus comunidades de residencia ante el clima de violencia que experimentaban, a lo que el 63\% manifestó que no. Incluso, al momento 
del levantamiento de la información, algunos de los desplazados realizaron señalamientos de que las mismas autoridades, particularmente de seguridad, eran las que se encontraban vinculadas al desarrollo de actividades del crimen organizado, y en el caso del $37 \%$ de las personas desplazadas que declararon haber buscado ayuda, mencionaron que después de su petición fueron hostigados por las mismas autoridades ante las denuncias realizadas (véase Gráfica 3).

\section{Gráfica 3.}

Mexicanos desplazados solicitantes de asilo que pidieron ayuda a las autoridades de sus comunidades de origen antes de huir. Ciudad Juárez, 2019

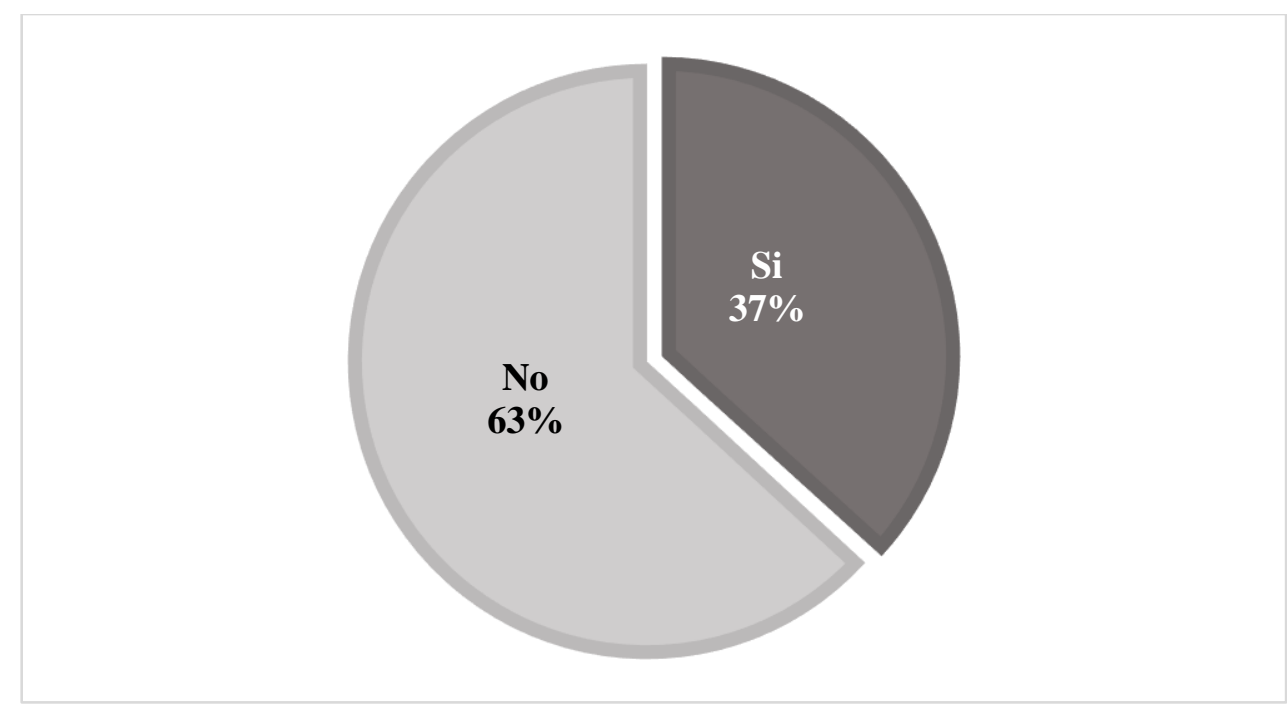

Fuente: Elaboración propia con base en la ENMEDESA, 2019.

El desplazamiento forzado interno no sólo significa que las personas tengan que huir ante el temor provocado por la violencia, sino que también se vean forzadas a abandonar sus bienes: casas, automóviles, tierras, incluso familiares. En este sentido, en el Cuadro 5 se observa que el $55.70 \%$ del total de desplazados que se encontraban en Ciudad Juárez mencionaron haber dejado su casa, el 14\% sus tierras y el $13.8 \%$ abandonaron su vehículo. Este contexto trae como consecuencia que las personas, al desplazarse, carezcan de recursos para un asentamiento posterior. Velázquez (2017) señala que la carencia de viviendas que experimentan los desplazados está vinculada con el abandono o la pérdida de sus propiedades, puesto que, al encontrarse amenazados por la violencia o habiéndola sufrido, no les queda más que huir dejando sus bienes inmuebles; al no existir mecanismos de protección que garanticen la seguridad física o jurídica de sus propiedades, las tienen que considerar perdidas. 


\section{Cuadro 5.}

Familiares y bienes que dejaros los mexicanos desplazados solicitantes de asilo en sus comunidades de residencia habitual. Ciudad Juárez, 2019

\begin{tabular}{ll}
\hline Familiares $\mathbf{y}$ bienes & $\mathbf{0}$ \\
\hline Familia de la tercera edad & $34.4 \%$ \\
Casa & $55.7 \%$ \\
Tierras & $14.8 \%$ \\
Automóvil & $13.8 \%$ \\
\hline Fuente: Elaboración propia con base en la ENMEDESA, 2019.
\end{tabular}

Aunque en México existen algunos avances en torno al reconocimiento del fenómeno del desplazamiento forzado interno, la realidad es que aún existen desafíos para la atención integral de las víctimas. Al no tener un diagnóstico para dimensionar y comprender el fenómeno, una figura legal de su reconocimiento ni la aprobación de una Ley Nacional sobre el Desplazamiento Forzado Interno, contribuye a que estás personas que huyen de sus comunidades se encuentren en contextos de alta vulnerabilidad, en un entorno de continua violación a sus derechos humanos y, sobre todo, permanecen invisibilizadas ante el Estado mexicano (CMDPDH, 2019). En este sentido, la solicitud de asilo para las personas que han tenido que huir de sus hogares por motivos de violencia se vuelve la mejor opción, al no encontrar protección por parte de las autoridades del Estado.

Otra de las preguntas realizadas a las personas desplazadas internas encuestadas fue la forma a través de la cual se enteraron del asilo, a lo que el 36\% respondió que tenían conocimiento por algún miembro de su comunidad de residencia, el 35\% por medio de un familiar, el 20\% por las redes sociales (esto al observar que migrantes extranjeros que se encontraban en alguna ciudad fronteriza estaban solicitando asilo), y el 3.8\% se enteró por algún miembro de su gobierno municipal. Aunque este último es un porcentaje bajo, es interesante analizar cómo algunas de las personas desplazadas señalan que las mismas autoridades municipales mexicanas los incitaron a que solicitaran asilo en Estados Unidos, incluso para contar con pruebas del temor fundado se identificó que personas provenientes de algunos municipios del estado de Michoacán, como Múgica, se les otorgaban constancias en donde las autoridades municipales certificaban que las familias eran víctimas de violencia derivada del crimen organizado, aludiendo a la incapacidad del Estado para proteger y garantizar la seguridad y libertad de las personas. 


\section{Gráfica 4.}

Forma en que se enteraron del proceso de asilo los mexicanos desplazados forzados. Ciudad Juárez, 2019

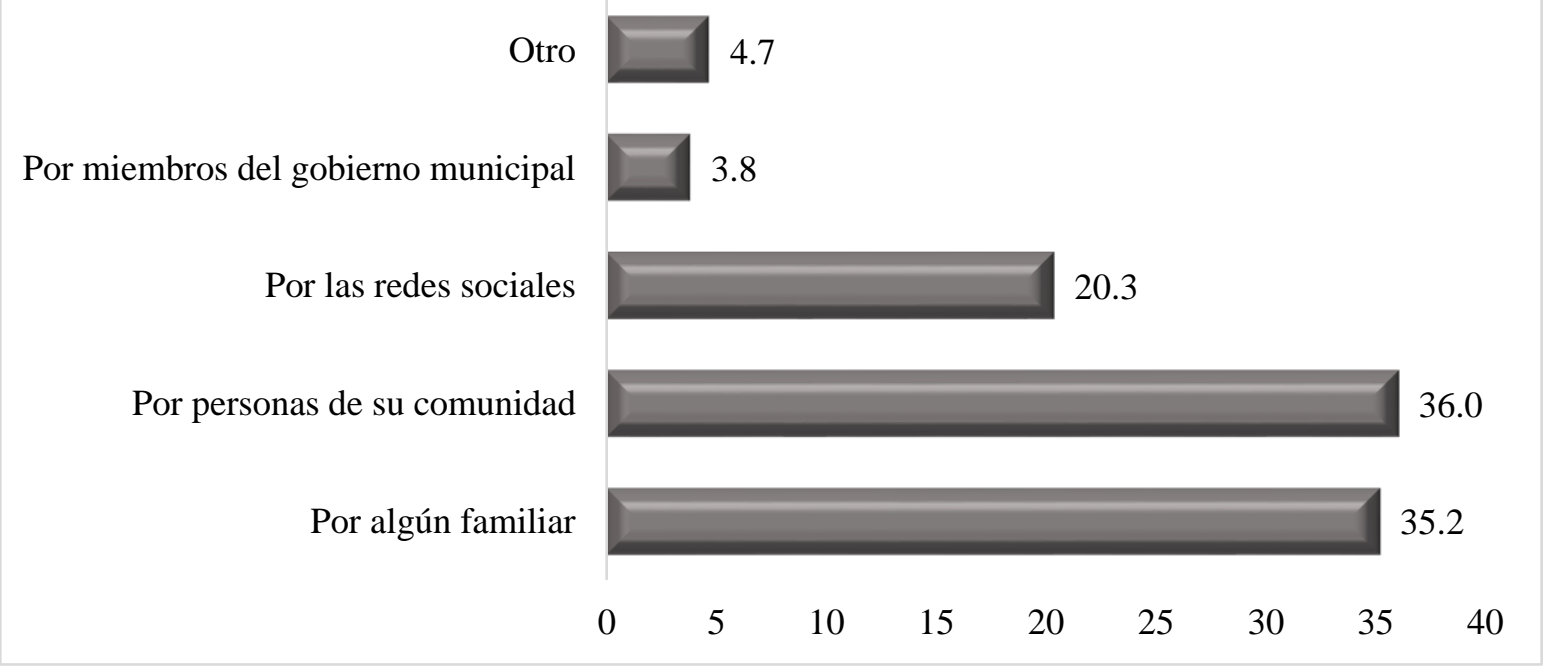

Fuente: Elaboración propia con base en la ENMEDESA, 2019.

Y si bien, la solicitud de asilo se convirtió en una opción de protección para los desplazados, la realidad es que la mayoría de las ocasiones únicamente quedó en ilusión y espejismo ante el contexto de adversidad que experimentaron en su lugar de origen, ya que, como fue señalado anteriormente, sólo el 3\% de los mexicanos obtienen un asilo afirmativo por parte de las autoridades estadounidenses. En este caso, el 59\% de las personas desplazadas forzadas internas señalaron que se encontraban esperando su turno para dar inicio a la petición de asilo, aunque no sabían en qué consistía ni tenían conocimiento de este proceso enmarcado en la política de inmigración de Estados Unidos; sólo el 41\% mencionó tener conocimiento de ello. Estos hallazgos también evidencian el nivel de desinformación de las personas, lo cual podría ser uno de los factores asociados a la baja aceptación de los casos presentados por parte de la población mexicana.

Finalmente, se exploró sobre las condiciones en las que se encontraban estas personas desplazadas forzadas internas solicitantes de asilo al momento del levantamiento de la información, así cómo cuáles eran sus expectativas con respecto al proceso de protección internacional. En este caso, se identificó que el 60\% de los encuestados se encontraban residiendo en casas de campaña, instaladas en la vía pública cerca de las inmediaciones de los puentes internacionales, algunos mencionaban que lo hacían por dos motivos; el primero es que no contaban con el recurso para acceder a una vivienda de alquiler, y el segundo, para estar cercanos y pendientes del número de personas que 
ingresaban de manera diaria ante las autoridades migratorias de Estados Unidos y que se respetara la secuencia que llevaban en la lista de registro. Esta lista o el "metering” es una técnica implementada por la Oficina de Aduanas y Protección Fronteriza de Estados Unidos (CBP por sus siglas en inglés), que limita la cantidad de personas autorizadas para acceder al proceso de asilo diariamente a través de los puertos de entrada oficiales y que comenzó a llevarse a cabo en febrero de 2016 (AIC, 2020). Por otra parte, también se destacó que además de las personas que se encontraban en las casas de campaña, el 26.3\% se hallaban a la intemperie, es decir, también estaban en las inmediaciones de los puentes internacionales, pero no contaban con una casa de campaña, por lo que dormían en las banquetas para dar continuidad a su turno e iniciar su proceso de solicitud de asilo. Finalmente, en menor medida también se identificó a personas desplazadas que se encontraban en albergues, rentando cuartos de hotel, particularmente en el centro de la ciudad, y un 3.3\% que se hospedaban en casas de familiares o amigos (véase Gráfica 5).

\section{Gráfica 5.}

Lugar en donde se hospedan los mexicanos desplazados solicitantes de asilo. Ciudad Juárez, 2019

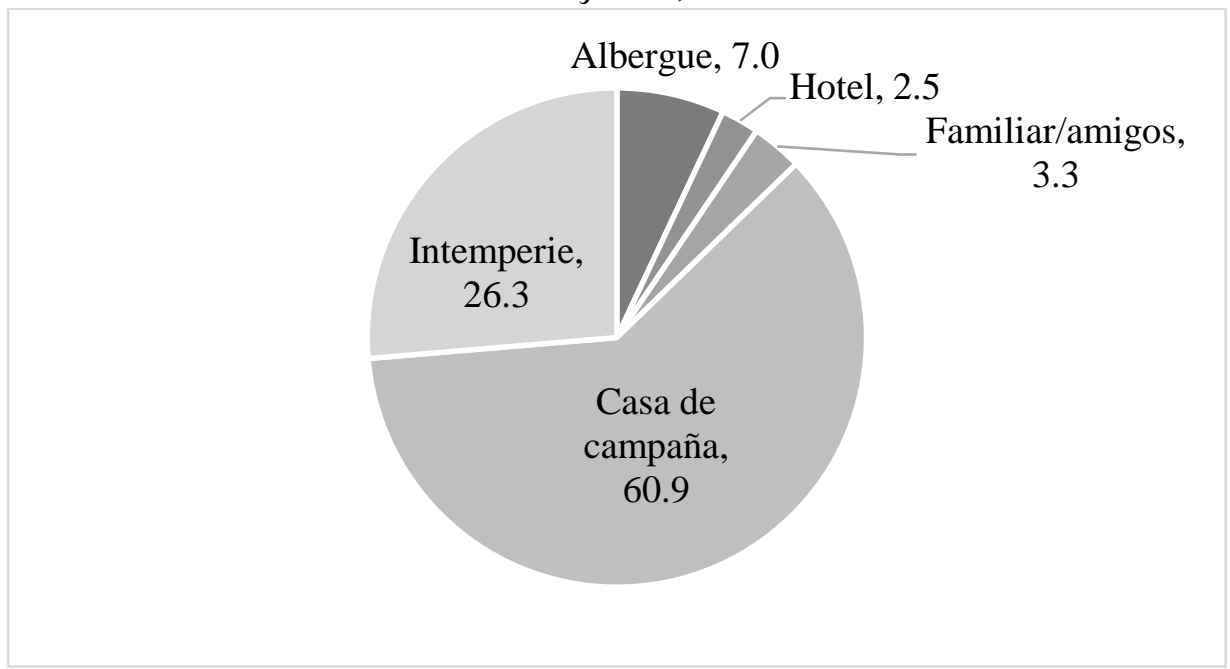

Fuente: Elaboración propia con base en la ENMEDESA, 2019.

Aunque las personas captadas a través de la ENMEDESA eran desplazadas forzadas internas con la intención de solicitar asilo, se logró captar cuales serían sus expectativas en caso de que este proceso de protección internacional no fuera favorable o desistieran del mismo. En la Gráfica 6 se muestra que el 38\% de las personas desplazadas mencionaron que no sabrían qué hacer o no lo habían pensado, lo que indica el grado de incertidumbre que sufren al insertarse en un proceso migratorio forzado, en donde el asilo es la única 
opción contemplada. Por otra parte, el 30\% dijo que en caso de que el asilo les fuera negado pensaban quedarse en Ciudad Juárez; el 10\%, radicar en otro lugar de México que no fuera el municipio de Juárez ni su comunidad huida, y el 9.9\% pensaba cruzar de manera irregular a Estados Unidos. Finalmente, el 10.3\% de los encuestados mencionó que regresaría a su comunidad de origen, lo que indica que sólo una persona de cada 10 desplazadas está dispuesta a regresar a sus hogar, aunque las razones de huida sigan presentes.

\section{Gráfica 6.}

Expectativas de los mexicanos desplazados solicitantes de asilo. Ciudad Juárez, 2019

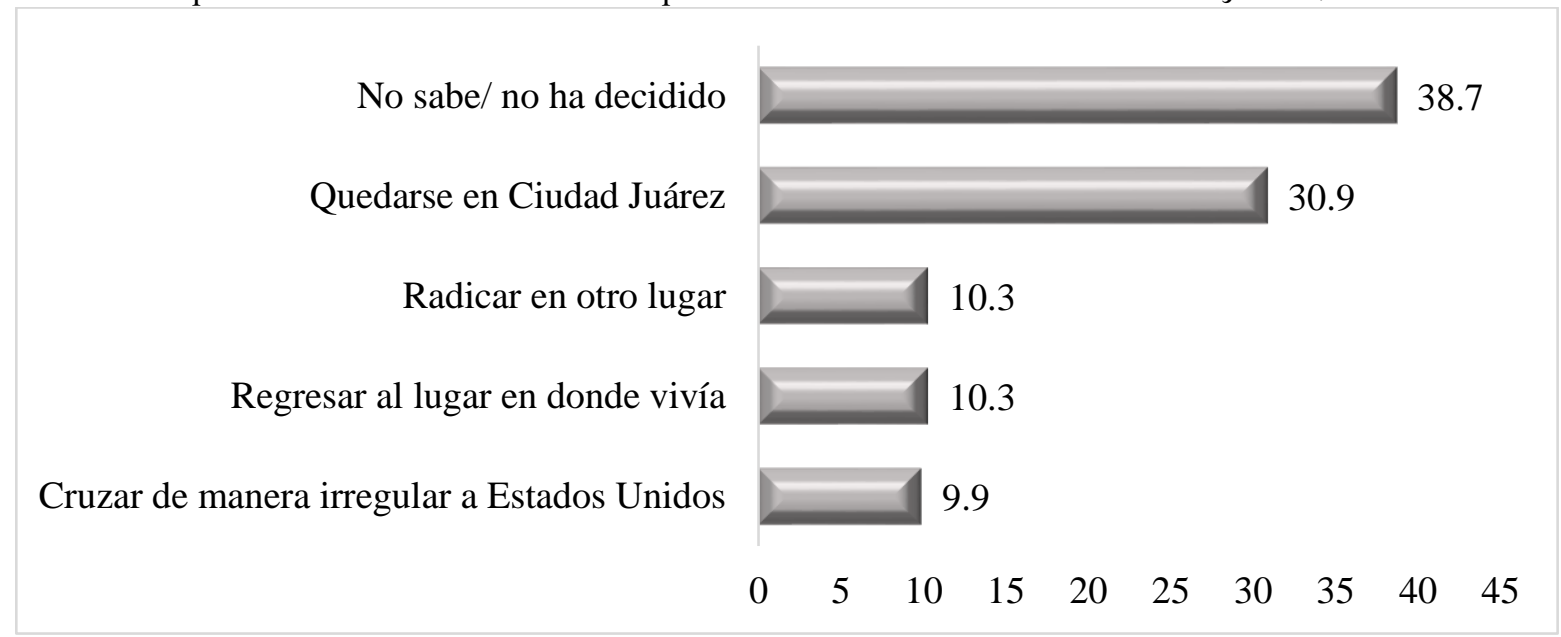

Fuente: Elaboración propia con base en la ENMEDESA, 2019.

La información presentada de la ENMEDESA, si bien da cuenta de algunas características sociodemográficas y del contexto de salida de personas desplazadas forzadas internamente, parte de su riqueza se centra en la captación de información sobre la intención de solicitar asilo por parte de sujetos que ya se encuentran bajo una categoría de migración forzada debido a su proceso de movilidad, motivada por contextos de violencia, es decir, que al momento de iniciar con su petición de asilo transitarán hacia otra categoría migratoria y con las bajas posibilidades existentes de obtener esta protección internacional por parte de las autoridades estadounidenses, nuevamente transitarán hacia una tercera categoría de migración forzada, que sería el retorno forzado al momento de ser repatriados con autoridades migratorias mexicanas. Esto demuestra la complejidad de los procesos migratorios originados por contextos de violencia, en donde los sujetos adquieren perfiles migratorios con alto grado de transitabilidad. Sin embargo, lo alarmante en estos procesos es que, ante este contexto de transitar de una 
categoría migratoria a otra, se desdibuja la responsabilidad de los Estados para atender, proteger y garantizar la seguridad y libertad de las personas migrantes forzadas.

\section{CONCLUSIONES}

Durante las últimas décadas, las migraciones forzadas han tomado un papel prominente en la movilidad contemporánea debido a su volumen y de ser resultado de contextos de violencia, crisis políticas o violaciones sistemáticas a los derechos humanos, lo que ha ocasionado la generación de categorías migratorias desde enfoques administrativo o jurídico y con la perspectiva de instrumentos internacionales que han permitido analizar, pero también atender a esta población migrante forzada. Sin embargo, hoy en día algunas de las movilidades superan a esas categorías establecidas, evidenciando la alta transitabilidad que puede tener un mismo sujeto respecto a las categorías de desplazamiento forzado interno, solicitantes de asilo, refugiados o retornados forzados, todo ocasionado también por las contradicciones del trinomio migración forzada, Estado y derecho.

En el contexto mexicano, el desplazamiento forzado interno es un fenómeno poco abordado; no obstante, los impactos que puede tener son de gran relevancia no sólo en la vida de las personas que se introducen en dicho proceso, sino en sus comunidades de origen, que quedan despobladas y en manos de grupos del crimen organizado. Al no existir un marco legal que ampare a los desplazados y que logre garantizar la protección requerida, no sólo evidencia la incapacidad de las autoridades de las comunidades de origen para promover la seguridad, protección y libertad de las personas, sino que las obliga a tener que buscar otras alternativas de protección, y lo hacen en otros países ocasionando una mayor complejidad del fenómeno. La transitabilidad de categorías migratorias mostradas en el presente artículo, sobre todo a partir de los resultados de la Encuesta de Mexicanos Desplazados Solicitantes de Asilo (ENMEDESA) de Ciudad Juárez, se comprende cuando personas de nacionalidad mexicana, en su mayoría, tuvieron que salir huyendo de sus comunidades ubicadas en Michoacán, Guerrero, Zacatecas, entre otras, por motivos de inseguridad, violencia por narcotráfico o persecución política, y que al no encontrar apoyo por parte de las autoridades tomaron la decisión de acudir a la frontera norte del país para iniciar un proceso de petición de asilo, el cual presenta altos niveles de rechazo, muchas veces como consecuencia de las condiciones de desinformación en las que llega esta población a las ciudades fronterizas, lo que ocasiona que vayan transitando de una categoría migratoria forzada a otra.

Clivajes. Revista de Ciencias Sociales (ISSN: 2395-9495), Año VIII, Núm. 15, enero-junio, 2021 Instituto de Investigaciones Histórico-Sociales, Universidad Veracruzana, México 
A manera de conclusión y con base en el análisis realizado con la ENMEDESA, se pueden destacar dos aspectos fundamentales; el primero, y más significativo debido al impacto que tendría directamente con la población en situación de movilidad forzada, es que es necesario poner sobre la mesa de los Estados dicha problemática con el objeto de generar mecanismos, estrategias o acciones de atención, protección y prevención de los desplazamientos a causa de la violencia e inseguridad pública; y el segundo, es que es indispensable reconocer que las categorías actuales muchas veces limitan la posibilidad de analizar de manera integral los procesos de movilidad forzada, ya que éstos las sobrepasan generando una alta transitabilidad por un mismo sujeto, es decir, una misma persona desplazada forzada interna, que fácilmente puede convertirse en solicitante de asilo y ante sistemas de asilo fragmentados, como el de Estados Unidos, donde las tasas de rechazo son numerosas, esta persona regresará a su país a través de un retorno forzado, por lo que es necesario revisar y reflexionar sobre las dimensiones y marcos analíticos bajo los cuales las categorías suelen ser construidas.

\section{REFERENCIAS}

Alvarado, S. y Massey, D. (julio, 2010). In Search of Peace: Structural Adjustment, Violence, and International Migration. The ANNALS of the American Academy of Political and Social Science 2010, 630(1), 137-161.

American Immigration Council (junio, 2020). Policies Affecting Asylum Seekers at the Border:The Migrant Protection Protocols, Prompt Asylum Claim Review, Humanitarian Asylum Review Process, Metering, Asylum Transit Ban, and How They Interact, Recuperado de https: / / bit.ly/3zwfnGW.

ARANGO, J. (octubre, 2003) La explicación teórica de las migraciones: luz y sombra en Revista Migración y Desarrollo, 1, 4-22.

Avendaño, R. M. (julio, 2016). Vidas en la incertidumbre: La migración forzada mexicana hacia la frontera norte de México ¿y nuestra solidaridad? Informe realizado por la Coalición pro defensa del migrante A.C. y American Friends Service CommitteLAC Recuperado de https: / / bit.ly/3HKOT7c.

BARrios, M. I. (2016). Movilidad humana en Ciudad Juárez, 2007-2012. Transitando de la inmigración laboral a la emigración y desplazamiento forzado. Tijuana: El Colegio de la Frontera Norte. 
BArrios, M. I., López, E. y Rubio, R. (2020). Flujos migratorios y Covid-19. La experiencia de los espacios filtro y de tránsito en Ciudad Juárez en Documento de Contingencia. El Colegio de la Frontera Norte. Recuperado en https: / / bit.ly/33bdSBD.

Bohra-Misha, P. y MASSEY, D. (mayo, 2011). Individual decisions to migrate during civil conflicto. Demography, 48(2), 401-424.

CASTLES, S. (octubre, 2003). La política internacional de la migración forzada. Migración y Desarrollo, 1, 1-28.

Chabat, J. (2010). La respuesta del gobierno de Calderón al desafío del narcotráfico: entre lo malo y lo peor. En Alvarado A. Y Serrano, M. (coords.), Seguridad nacional y seguridad interior, Los grandes problemas de México (pp. 21-40). El Colegio de México.

Cohen, R. (agosto, 1998). Los principios rectores de los desplazamientos internos: un nuevo instrumento para las organizaciones internacionales y las ONG en Migraciones forzosas incorpora la RPN, 2, 31-33.

Comisión Mexicana de Defensa y Promoción de los Derechos Humanos (2018). Episodios del Desplazamiento interno forzado Masivo en México. Recuperado de https: / / bit.ly/3n43cvL.

Escobar, Agustin (2003). Migration and Development in North and Central America: a Synthetic View. IOM/ECFLAC/CELADE. Recuperado de https: / / bit.ly/3q2o1tJ.

FitzGerald, D. (2019). Refuge beyond Reach: How Rich Democracies Repel Asylum Seekers. Oxford University Press.

GonZÁleZ, M. (abril, 2002). Desterrados: el desplazamiento forzado sigue aumentado en Colombia. Revista convergencia, 27, 41-78.

Gortázar, C. (1997). Derecho de asilo y "no rechazo" al refugiado. Universidad Pontifica de Comillas, Dykinson.

IGI-MEX (2016). Índice Global de Impunidad en México. Centro de Estudios sobre Impunidad y Justicia, Universidad de las Américas. Recuperado de https: / / bit.ly/3foDkMV.

Herrera, R. (2006). La perspectiva teórica en el estudio de las migraciones. Siglo XXI Editores.

KäLIN, W. (1998). Guiding Principles on Internal Displacement. Annotations. Studies. Trasnational Legal Policy, 38. Recuperado de https: / / brook.gs/3JKthKa.

LeE, E. (1966). A theory of migration. Demography, 3(1), 47- 53. 
López, E. A., JuÁrez, L.G., y Veytia, M.G. (junio, 2019). Esquema tipológico de las migraciones y desplazamientos forzados. Estudios Fronterizos, 20(e028), 1-21.

Miron, J. A. (octubre, 2001). Violence, Guns, and Drugs: A Cross-Country Analysis. Journal of Law and Economics, 44(52), 615-633.

MORRISON, A. (julio, 1993). Violence or Economics: What drives and internal migration in Guatemala. Economic Development and cultural Change, 41(4), 817-831.

Moreno, J., Galván, M. Y SiU, E. (mayo, 2015). Los migrantes internos desplazados por la violencia. Revista de información y pastoral migratoria, año XXI, 20-23.

ORGANIZACIÓN INTERNACIONAL PARA LAS MigRACIONES (2006). Glosario sobre migración. Recuperado de https://bit.ly/3t2k227.

ORgANIZACIÓN INTERNACIONAL PARA LAS MigRACIONES (2020). Informe sobre las migraciones en el Mundo 2020. Recuperado de https: / / bit.ly/3HFWwfb.

Patiño, G. Y Herrán, O. (noviembre, 2012). Desplazamiento forzado, niñez y adolescencia: escenarios en relación con su estabilidad socioeconómica. Revista Salud pública, 14(2), 58-68.

Plan Nacional de Desarrollo (PND) 2007-2017, Recuperado de https: / / bit.ly/34tscGx. RAMíREZ, T. Y MEZA, L (2012). Inseguridad pública y migración internacional en México. En Ramírez, T. y Castillo, M. A. (coords.), El estado de la migración. México ante los recientes desafíos de la migración internacional (pp. 269-298). Consejo Nacional de Población.

Ravenstein, E. G. (junio, 1885). The laws of migration. Journal of the Statiscal Society of London, 48(2), 167-235.

Rondanini, A. (2007). El derecho a solicitar asilo, en Derechos Humanos (pp. 221-233). Fundación de Derecho Administrativo.

SIRKECI, I. (septiembre, 2005). War in Iraq: Environment of Insecurity and International Migration. International Migration Review, 43(4), 197-212.

VELÁzQUEZ, S. (febrero, 2012). Desplazamientos forzados: migración e inseguridad en Ciudad Juárez, Chihuahua. Cuadernos de Trabajo UACJ, 7, 3-21.

Velázquez, A. L. (2017). Desplazamiento interno por violencia en México. Causas, consecuencias y responsabilidad del Estado. Comisión Nacional de los Derechos Humanos.

Wood, C., Gibson, C., Ribeiro, L., Hamsho-Díaz, P. (junio, 2010). Crime Victimization in Latin America and intentions to migrate to the United States. International Migration Review, 44(1), 3-24. 